Southern Illinois University Carbondale

OpenSIUC

Publications

Department of Physics

$10-2004$

\title{
Real-time Spectroscopic Ellipsometry Study of Ultrathin Diffusion Barriers for Integrated Circuits
}

S M. Aouadi

Southern Illinois University Carbondale

P K. Shreeman

Southern Illinois University Carbondale

MWilliams

University of Illinois at Urbana-Champaign

Follow this and additional works at: http://opensiuc.lib.siu.edu/phys_pubs

(c) 2004 American Institute of Physics

Published in Journal of Applied Physics, Vol. 96 No. 7 (2004) at 10.1063/1.1784621

\section{Recommended Citation}

Aouadi, S M., Shreeman, P K. and Williams, M. "Real-time Spectroscopic Ellipsometry Study of Ultrathin Diffusion Barriers for Integrated Circuits." (Oct 2004).

This Article is brought to you for free and open access by the Department of Physics at OpenSIUC. It has been accepted for inclusion in Publications by an authorized administrator of OpenSIUC. For more information, please contact opensiuc@lib.siu.edu. 


\title{
Real-time spectroscopic ellipsometry study of ultrathin diffusion barriers for integrated circuits
}

\author{
S. M. Aouadia) and P. K. Shreeman \\ Department of Physics, Southern Illinois University, Carbondale, Illinois 62901-4401 \\ M. Williams \\ Frederick Seitz Materials Research Laboratory, University of Illinois, Urbana, Illinois 61801
}

(Received 19 April 2004; accepted 29 June 2004)

\begin{abstract}
The objective of this work is to monitor the growth process and the thermal stability of ultrathin tantalum nitride barrier nanostructures against copper diffusion in integrated circuits using real-time spectroscopic ellipsometry (RTSE). Single layers of copper and bilayer films of copper and tantalum nitride were produced on $\mathrm{Si}(111)$ substrates using unbalanced magnetron sputtering. The RTSE data was simulated using the Bruggeman effective medium approximation and a combined Drude-Lorentz model to obtain information about the growth process, film architecture, interface quality, and the conduction electron transport properties for these structures. The results deduced from the RTSE were verified by characterizing the structural and the chemical properties of the fabricated films using x-ray diffraction, Auger electron spectroscopy, and Rutherford backscattering. The effectiveness of the tantalum nitride barrier to stop the diffusion of copper into silicon was evaluated, monitoring their optical properties when annealed at $720{ }^{\circ} \mathrm{C}$. The dielectric function of the films changed from a metallic to an insulating character when the diffusion proceeded. Also, the RTSE provided valuable information about the microstructure and the kinetics of the phase transformations that occur during heat treatment. (C) 2004 American Institute of Physics. [DOI: 10.1063/1.1784621]
\end{abstract}

\section{INTRODUCTION}

Copper has replaced aluminum as the metallization material for advanced integrated circuits because of its superior electrical conductivity and electromigration resistance. ${ }^{1,2}$ However, copper diffuses readily into silicon and forms $\mathrm{Cu}_{3} \mathrm{Si}$ at temperatures as low as $200{ }^{\circ} \mathrm{C}$. Barriers are therefore required between $\mathrm{Cu}$ and $\mathrm{Si}$ to prevent this diffusion. The refractory metals and their nitrides have been investigated for such applications. ${ }^{3-5}$ For instance, tantalum and tantalum nitride have been studied the most owing to their immiscibility with $\mathrm{Cu}$ and their superior thermal stability. ${ }^{6} \mathrm{~A}$ new challenge facing the semiconductor industry is that the dimensions of $\mathrm{Cu}$ interconnected structures continue to shrink, forcing the dimensions of barrier layers to scale down. Consequently, investigating the reliability of ultrathin structures becomes more and more important for the product reliability. The reliability of these structures is a function of the physical and the chemical properties of the fabricated materials that also depend on the process parameters. Though the properties of Ta-based films with layer thicknesses of $50 \mathrm{~nm}$ and more have been studied in the past, less is known about the relation between growth process/ structure/thermal stability of much thinner barriers. ${ }^{7}$

An ideal means of studying the nucleation and the growth phenomena of these nanostructures is through realtime optical methods. More specifically, real-time spectroscopic ellipsometry (RTSE) would be an excellent candidate

\footnotetext{
a) Author to whom correspondence should be addressed; electronic mail: saouadi@physics.situ.edu
}

for the study of $\mathrm{Cu} /$ barrier/Si structures ( $\mathrm{Si}$ being the substrate). The RTSE is an optical technique and therefore offers the advantage of being nondestructive and noninvasive. In addition, the optical properties of a material carry information that pertains to its chemical, structural, and transport properties with a submonolayer resolution. ${ }^{8,9}$ These are very desirable quantities when designing or investigating such structures. Furthermore, the electrical resistivity and the mean free path (MFP) of conduction electrons may be deduced as a function of thickness from analyzing the RTSE data with a Drude-Lorentz (DL) oscillator model. ${ }^{8,9}$ Hence, the deposition conditions may be altered to minimize resistivity, which is so crucial during the fabrication of ultrathin films for interconnects.

The objective of this study was to develop the RTSE as an analytical technique to monitor (1) the growth of $\mathrm{Cu} / \mathrm{TaN}_{x} / \mathrm{Si}$ ultrathin nanostructures and (2) their reliability at high temperature. These studies are essential to transferability, scale-up, and reproducibility of new processes being developed to produce the next generation of electronic nanodevices. To achieve this goal, these structures were deposited on (111) silicon wafers. The RTSE was used to deduce architecture, chemical composition, and electron-transport properties of these materials. In addition, it was used to monitor any changes in the optical signature of the films as a result of their annealing at $720{ }^{\circ} \mathrm{C}$ for $1.5 \mathrm{~h}$.

\section{EXPERIMENTAL DETAILS}

Single layers of copper $(\mathrm{Cu} / \mathrm{Si})$ and bilayers of copper on tantalum nitride $\left(\mathrm{Cu} / \mathrm{TaN}_{x} / \mathrm{Si}\right)$ films were deposited by 
TABLE I. Deposition conditions of the $\mathrm{Cu} / \mathrm{Si}$, the $\mathrm{Cu} / \mathrm{Ta}-\mathrm{N} / \mathrm{Si}$, and the $\mathrm{Cu} / \mathrm{TaN} / \mathrm{Si}$ structures.

\begin{tabular}{lccc}
\hline \hline Sample & $\begin{array}{c}\text { Deposition time } \\
\text { for Cu(min) }\end{array}$ & $\begin{array}{c}\text { Deposition time } \\
\text { for Ta-N(min) }\end{array}$ & $\begin{array}{c}\text { Nitrogen flow rate } \\
\text { for Ta-N (sccm) }\end{array}$ \\
\hline S1 & 3.0 & - & - \\
S2 & 2.5 & 2.5 & 0.5 \\
S3 & 2.5 & 4.5 & 2.4 \\
\hline \hline
\end{tabular}

unbalanced magnetron dc sputtering onto polished (111)oriented single crystal silicon. The sputtering system consisted of a cylindrical stainless steel chamber that is $380 \mathrm{~mm}$ in diameter and $420 \mathrm{~mm}$ high, three $50 \mathrm{~mm}$ UHV magnetron source, and a sample insertion load lock. The coatings were grown using a $\mathrm{Cu}$ and a Ta target (99.99\% purity) in an $\mathrm{Ar}$ $(99.999 \%)$ discharge. Before deposition, all substrates were ultrasonically cleaned in methanol and acetone for $5 \mathrm{~min}$ each and then dried with pure $\mathrm{N}_{2}$.

A system pressure of $1 \times 10^{-5} \mathrm{~Pa}$ was achieved prior to each film deposition. A mass flow controller was utilized to regulate the amount of Ar supplied into the chamber during the deposition. The Ar pressure was set to $0.26 \mathrm{~Pa}(2$ $\times 10^{-3}$ Torr) and the power to the $\mathrm{Cu}$ and Ta targets were set to 25 and $100 \mathrm{~W}$, respectively. The substrate was adjusted vertically to establish a substrate-to-target distance of $10 \mathrm{~cm}$. During the growth of both materials, a radio frequency power supply was set to provide a substrate bias voltage of $-70 \mathrm{~V}$. The substrate ion current density was measured to be $2 \mathrm{~mA} / \mathrm{cm}^{2}$. The growth conditions explored in this paper included deposition time and nitrogen flow rate (reactive sputtering of $\mathrm{TaN}_{x}$ ), as shown in Table I. In this table and throughout the paper, Ta-N (S2) refers to the $\mathrm{TaN}_{x}$ film produced using a low-nitrogen flow rate $(0.5 \mathrm{sccm})$ and $\mathrm{TaN}$ (S3) refers to the one fabricated using a high rate $(2.4 \mathrm{sccm})$. The fabricated samples were subsequently annealed in the same sputter chamber. The quartz iodine lamps heated the sample in the chamber through a fused silica window.

The RTSE measurements were carried out during deposition to understand the growth process of copper films and during annealing to monitor the changes in the optical properties of the film during the formation of copper silicide.

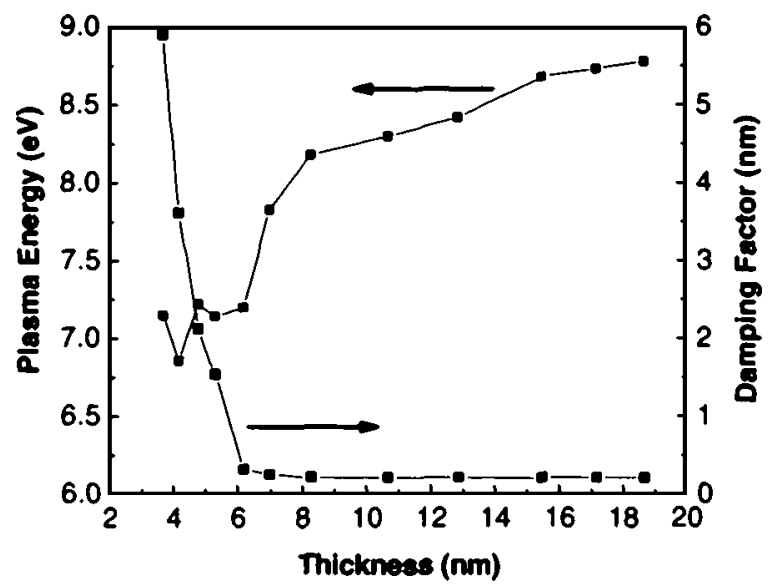

FIG. 1. Unscreened plasma energy and the damping factor as a function of thickness for a sputter-deposited $\mathrm{Cu} / \mathrm{Si}$ film.

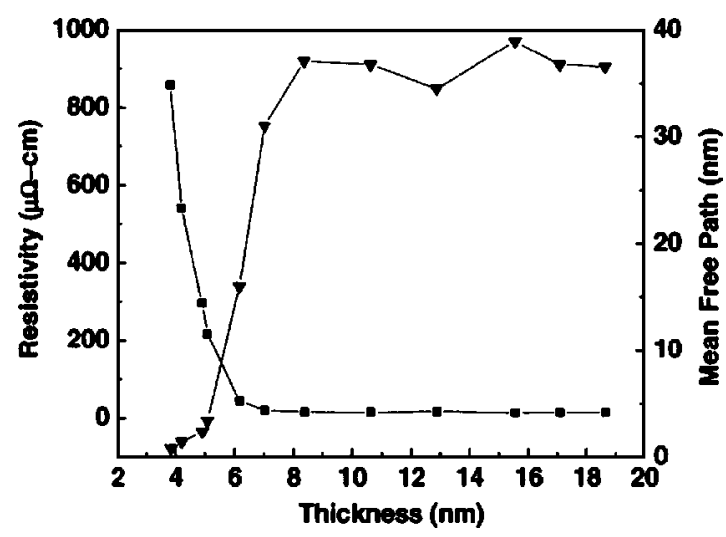

FIG. 2. Electrical resistivity and the mean free path of conduction electrons as a function of thickness for a sputter-deposited $\mathrm{Cu} / \mathrm{Si}$ film.

These measurements were carried out using a Woollam Co., Inc. M-2000 variable angle spectroscopic ellipsometer equipped with WVASE32 $2^{\mathrm{TM}}$ and $\mathrm{EASE}^{\mathrm{TM}}$ softwares to record the optical spectra of the films for photon energies in the range from 1.2 to $3.3 \mathrm{eV}$ and an angle of incidence of $63.8^{\circ}$.

The crystallographic structure of the films was analyzed using a $1.54 \AA$ wavelength $\mathrm{Cu} \mathrm{K} \alpha$ radiation with a Rigaku $\mathrm{X}$-ray diffractometer and a graphite-diffracted beam monochromator. All the spectra were taken with an accelerating voltage of $45 \mathrm{kV}$ and a current of $20 \mathrm{~mA}$. The chemical analysis of the selected films was performed using Rutherford back scattering spectroscopy (RBS) and Auger electron spectroscopy (AES). RBS was carried out with a $2-\mathrm{MeV}$ incident $\mathrm{He}^{+}$beam. The experimental results were compared with the theoretical simulation fittings made with a RUMP program. ${ }^{10}$ AES measurements were performed with a Physical Electronics PHI 660 scanning Auger microprobe equipped with a secondary electron detector. The background and operating pressures used were $5 \times 10^{-8} \mathrm{~Pa}(4$ $\times 10^{-10}$ Torr $)$ and $2 \times 10^{-6} \mathrm{~Pa}\left(1 \times 10^{-8}\right.$ Torr $)$, respectively. Depth profiling was performed by etching the sample using a $1 \mathrm{keV}$ Ar beam with a current density of $40 \mu \mathrm{A} / \mathrm{cm}^{2}$. The $\mathrm{LaB}_{6}$ filament electron gun operating at $10 \mathrm{keV}$ was used to excite the samples.

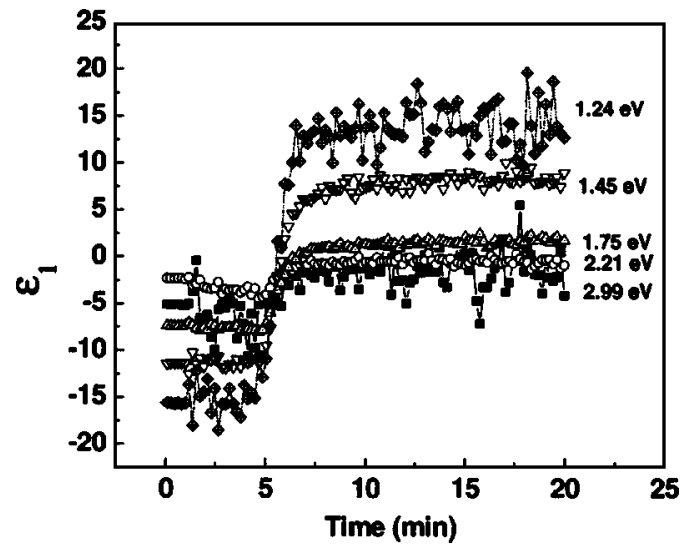

FIG. 3. SE dynamical data measured during the heat treatment of $\mathrm{Cu} / \mathrm{Si}$ films. 

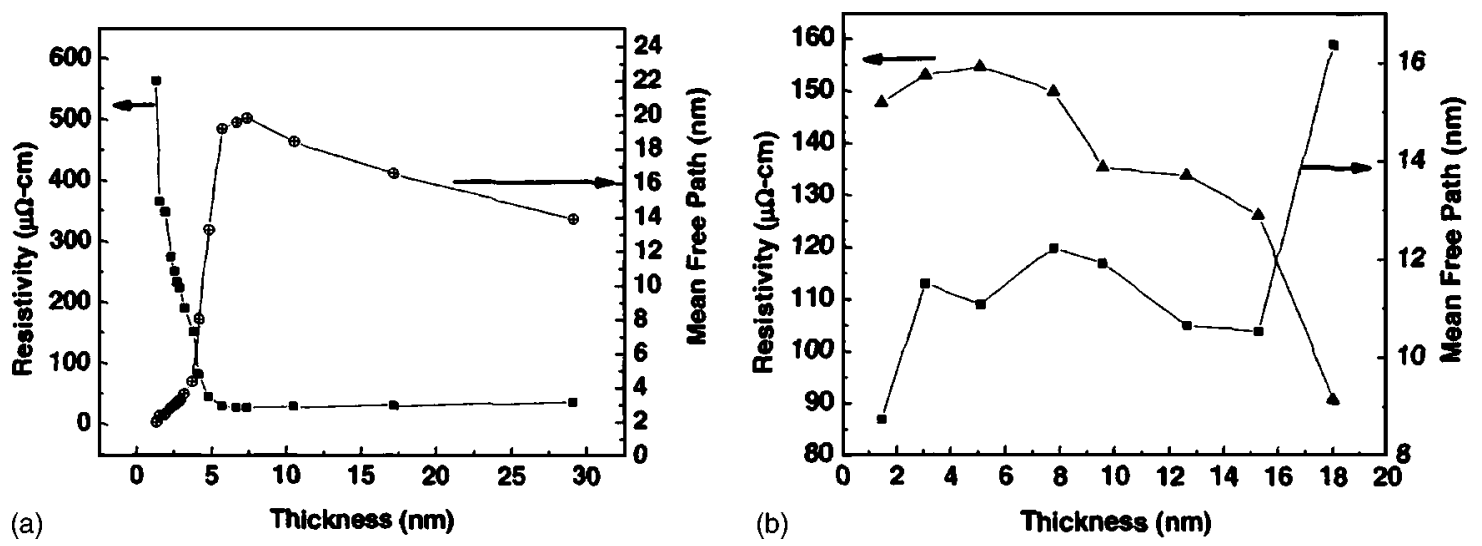

FIG. 4. Electrical resistivity and the mean free path of conduction electrons as a function of the thickness of (a) Cu layer and (b) Ta-N layer for sample S2.

\section{RESULTS AND DISCUSSION}

\section{A. $\mathrm{Cu} / \mathrm{Si}$ System}

RTSE was used to monitor the deposition of $\mathrm{Cu} / \mathrm{Si}(\mathrm{S} 1)$. An additional "thick" $\mathrm{Cu}$ film was deposited and was used as a reference for pure $\mathrm{Cu}$ when carrying out RTSE data analysis. The dynamical data was simulated using a multilayer model, which mimics the growth process.

1. From $t=0.0$ to $0.4 \mathrm{~min}$ : The spectrum describes a bare silicon with a native oxide layer of $2.37 \pm 0.03 \mathrm{~nm}$. The shutter was opened at the end of this time period to start the growth of the film.

2. From $t=0.4$ to 0.9 min: The layer was assumed to be a mixture of copper silicide $\left(\mathrm{Cu}_{3} \mathrm{Si}\right)$ and silicon dioxide $\left(\mathrm{SiO}_{2}\right)$ at a growth rate of $10.0 \pm 1.0 \mathrm{~nm} / \mathrm{min}$. The mixture was simulated using a Bruggeman effective medium approximation (BEMT). ${ }^{11}$ The dielectric function of $\mathrm{Cu}_{3} \mathrm{Si}$ was measured after the heat treatment of this sample at $400{ }^{\circ} \mathrm{C}$ (the surface remained smooth at this temperature). The total thickness of this layer was calculated to be $5.0 \pm 1.0 \mathrm{~nm}$.

3. From $t=0.9$ to $3.4 \mathrm{~min}$ : The last stage corresponds to the deposition of pure $\mathrm{Cu}$ at a growth rate of $8.0 \pm 0.4 \mathrm{~nm} / \mathrm{min}$ and a total thickness of $20.0 \pm 1.0 \mathrm{~nm}$.

The evolution of the transport properties of Cu's conduction electrons may be established by analyzing its dielectric function using the contributions of intraband and interband transitions described by the DL oscillator model. ${ }^{12}$ The DL model is based on the assumption that the response of electrons in a material to a driving electric field is similar to the response of a harmonic oscillator subject to a dissipative force. The dielectric function is thus given by

$$
\varepsilon(E)=\varepsilon_{1}+i \varepsilon_{2}=\varepsilon_{1 \infty}+\sum_{i=1}^{N} \frac{A_{k}}{E_{k}^{2}-(h \nu)^{2}-i B_{k} h \nu},
$$

where $\mathcal{E}(E)$ is the dimensionless complex dielectric function, $\mathcal{E}_{1 \propto}$ is the real part of the dielectric function at very large photon energies, and $N$ is the total number of oscillators. Each oscillator is described by three parameters: $A_{i}$ (in $\mathrm{eV}^{2}$ ), $B_{i}$ (in $\mathrm{eV}$ ), and $E_{i}$ (in $\mathrm{eV}$ ), which are the amplitude, the broadening, and the center energy of the $i$ th oscillator, respectively. The dielectric function of $\mathrm{Cu}$ was modeled using a single-layer model as a superposition of a Drude term ( $E_{k}=0$ in the previous equation) and two Lorentz oscillators. The Drude term is depicted by the unscreened plasma energy $E_{\mathrm{pu}}=\sqrt{A_{1}}$ and the damping factor $B_{1}$. The unscreened plasma energy depends on the concentration of conduction electrons and is defined by

$$
E_{\mathrm{pu}}=\sqrt{A_{1}}=\sqrt{\frac{N e^{2}}{\varepsilon_{0} m^{*}}}
$$

where $\hbar$ is the Planck's constant, $N$ is the density of the conduction electron, $\varepsilon_{0}$ is the charge of an electron, $\mathcal{E}_{0}$ is the permittivity of free space, and $m^{*}$ is the electron effective
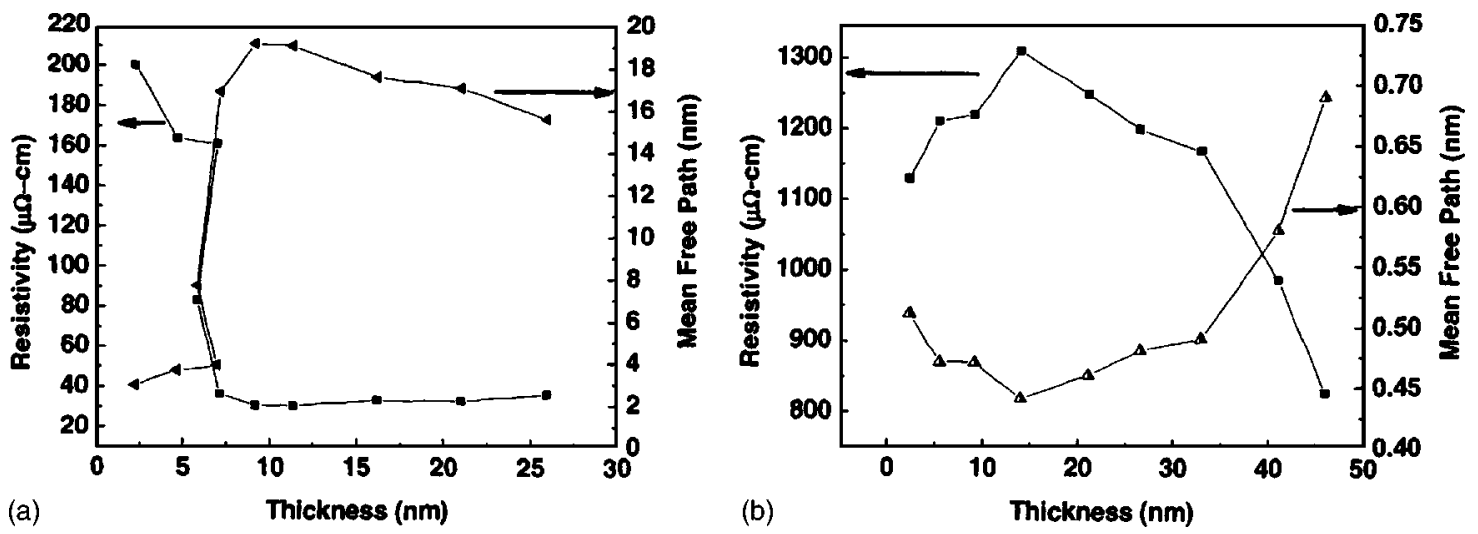

FIG. 5. Electrical resistivity and the mean free path of conduction electrons as a function of the thickness of (a) Cu layer and (b) TaN layer for sample S3. 


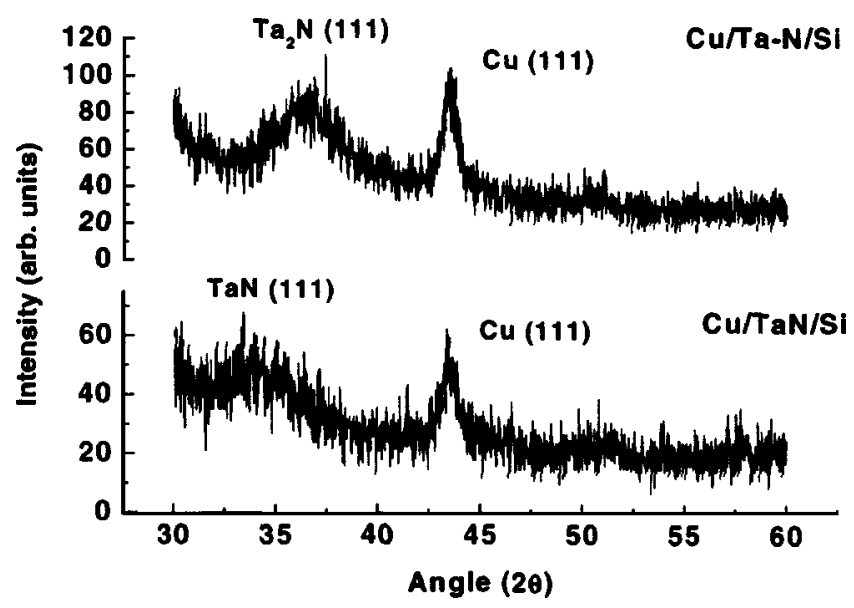

FIG. 6. XRD data for the $\mathrm{Cu} / \mathrm{Ta}-\mathrm{N} / \mathrm{Si}$ and the $\mathrm{Cu} / \mathrm{TaN} / \mathrm{Si}$ films.

mass. The damping factor is due to the scattering of electrons and is the inverse of the conduction electron relaxation time $\tau .^{12}$ The evolution of the unscreened plasma frequency and the damping factor are shown in Fig. 1. The calculated values of $E_{\mathrm{pu}}$ at the initial stages of growth are lower than the values at the subsequent times because of the following: (1) the surface plasmon of the conduction electrons, (2) the high defect density due to the intermixing at the interface, and (3) the 3D-island or Volmer-Weber mode of growth of $\mathrm{Cu} .{ }^{13}$ In contrast, the values of $B_{1}$ decreased dramatically with thickness. In fact, $B_{1}$ has a relatively large value at the initial stages of growth because of the initial growth mode (island growth) and the impurity incorporation due to the intermixing. ${ }^{13,14}$ For the $\mathrm{Cu}$ growth on $\mathrm{Si}$ or $\mathrm{SiO}_{2}$ substrates, the $\mathrm{Cu}-\mathrm{Cu}$ interaction energy is stronger than the interfacial energy between the $\mathrm{Cu}$ and the substrate, i.e., $\mathrm{Cu}$ does not wet the substrate and $\mathrm{Cu}$ islands form. The evolution of the electrical resistivity and the MFP of conduction electrons were calculated from $E_{\mathrm{pu}}$ and $B_{1}$ and are shown in Fig. 2. ${ }^{12}$ The resistivity decreased while the electron MFP increased with thickness, which is expected during the initial stages of growth of such thin films. ${ }^{14,15}$ Both values remained constant $(\rho=14.9 \mu \Omega \mathrm{cm}$ and $\mathrm{MFP}=36 \mathrm{~nm})$ once a threshold thickness was obtained $(\approx 10 \mathrm{~nm})$. Numerous groups have measured the resistivity of $\mathrm{Cu}$ films and lines in the sub-100 nm

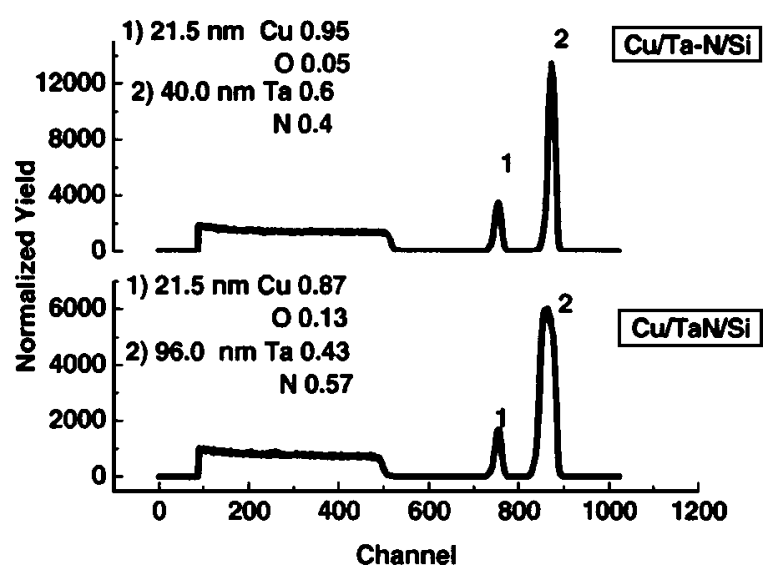

FIG. 7. RBS spectra of the as-deposited $\mathrm{Cu} / \mathrm{Ta}-\mathrm{N} / \mathrm{Si}$ and the $\mathrm{Cu} / \mathrm{TaN} / \mathrm{Si}$ films.

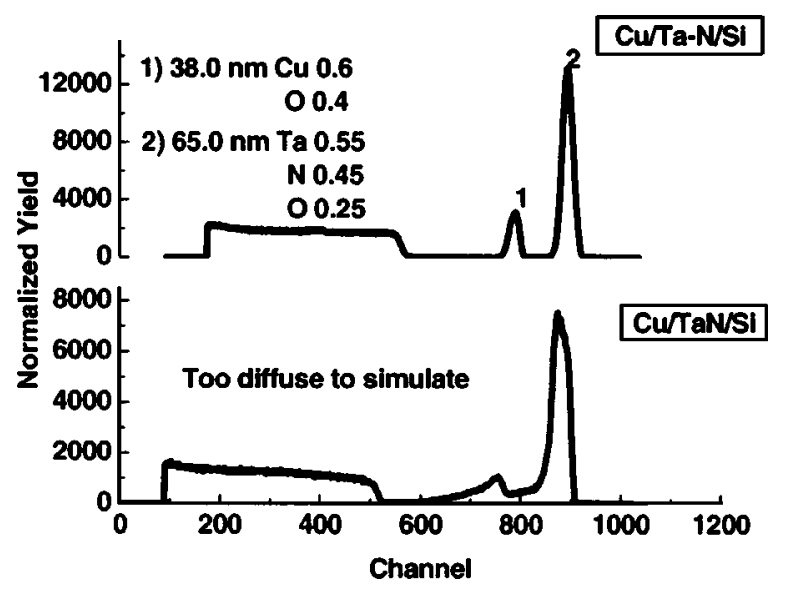

FIG. 8. RBS spectra of the annealed $\mathrm{Cu} / \mathrm{Ta}-\mathrm{N} / \mathrm{Si}$ and the $\mathrm{Cu} / \mathrm{TaN} / \mathrm{Si}$ films.

size regime using the four-point probe technique and have reported similar results. ${ }^{14-17}$

For the very thin films (thicknesses $<100 \mathrm{~nm}$ ), several effects alter the transport properties from the intrinsic or the bulk value, which is mostly due to phonon scattering. ${ }^{14}$ The reader is encouraged to consult an excellent review on the subject that was recently published by Rossnagel and Kuan. ${ }^{14}$ These effects include impurity incorporation, grain size, grain boundaries, surface roughness, and size effect due to electron-surface scattering. The authors also provided the following expression for the resistivity $\rho$ as a function of thickness $d$ :

$$
\frac{\rho}{\rho_{0}}=1+0.375(1-p) S \lambda / d+1.5\left(\frac{R}{1-R}\right) \lambda / g,
$$

where $\rho_{0}$ is the bulk resistance, $\lambda$ is the electron MFP, $d$ is the thickness of the film, $p$ is the scattering parameter ( 0 for fully diffuse and 1 for fully elastic scattering), $S$ is a surface factor estimated from a Monte Carlo model, $g$ is the average grain size, and $R$ is the scattering coefficient ( 0 for complete electron transmission and 1 for complete scattering by the boundary). The effect of impurities on the transport properties of the films are not incorporated in this model and are expected to have a tremendous impact on the initial stages of growth of our samples given that their deposition conditions promoted the interface mixing.

The deposited film was heat-treated in vacuum. The temperature was increased between room temperature and $400{ }^{\circ} \mathrm{C}$ with a ramp rate of $150{ }^{\circ} \mathrm{C} / \mathrm{min}$. The temperature was then kept at $400{ }^{\circ} \mathrm{C}$ for $1.5 \mathrm{~h}$. Shown in Fig. 3 is the dynamical data for a selected period of time that highlighted a change in the optical constants. This figure revealed that the dielectric function of the film varied considerably between $t=3$ and $6 \mathrm{~min}$. This variation in the optical response of the film was probably due to the diffusion process (reaction between $\mathrm{Cu}$ and $\mathrm{Si}$ ) that was initiated when the temperature reached $400{ }^{\circ} \mathrm{C}(t=2.6 \mathrm{~min})$. The values of the dielectric functions leveled off at $t=6 \mathrm{~min}$, indicating that all the

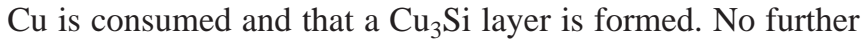
changes were observed during the remainder of the annealing process. In addition, Fig. 3 indicated that the dielectric function changed from the metallic character of $\mathrm{Cu} / \mathrm{Si}$ to the 
TABLE II. Thickness and composition of the $\mathrm{Cu} / \mathrm{Ta}-\mathrm{N} / \mathrm{Si}$ and the $\mathrm{Cu} / \mathrm{TaN} / \mathrm{Si}$ determined from the RBS.

\begin{tabular}{lcccc}
\hline \hline Sample & $\begin{array}{c}\text { Thickness } \\
\text { of } \mathrm{Cu}(\mathrm{nm})\end{array}$ & $\begin{array}{c}\mathrm{Thickness} \\
\text { of } \mathrm{TaN}_{\mathrm{x}}(\mathrm{nm})\end{array}$ & $\begin{array}{c}\text { Composition } \\
\text { of } \mathrm{Cu}\end{array}$ & $\begin{array}{c}\text { Composition } \\
\text { of } \mathrm{TaN}_{x}\end{array}$ \\
\hline S2 before HT & $21 \pm 2$ & $36 \pm 4$ & $\mathrm{CuO}_{0.006}$ & $\mathrm{TaN}_{0.5}$ \\
S2 after HT & $38 \pm 4$ & $65 \pm 4$ & $\mathrm{CuO}_{0.67}$ & $\mathrm{TaN}_{0.81} \mathrm{O}_{0.45}$ \\
S3 before HT & $21 \pm 2$ & $96 \pm 10$ & $\mathrm{CuO}_{0.15}$ & $\mathrm{TaN}_{1.33}$ \\
S3 after HT & - & - & - & - \\
\hline \hline
\end{tabular}

insulating character of $\mathrm{Cu}_{3} \mathrm{Si}$ because the values of the real part of the dielectric function at the lower energy end of the spectrum moved progressively from negative to positive values.

The evolution of the dielectric function with heattreatment time was simulated using the BEMT model. The following two-layer model was used: (1) the underlayer consisted of a mixture of $\mathrm{Cu}$ and $\mathrm{Cu}_{3} \mathrm{Si}$ and (2) the overlayer depicted a roughness layer that was simulated as a mixture of voids $(50 \%)$ and the underlayer material (50\%). The BEMT model revealed that the film changed gradually from a pure $\mathrm{Cu}$ to a mixture of $\mathrm{Cu} / \mathrm{Cu}_{3} \mathrm{Si}$ and finally to a pure $\mathrm{Cu}_{3} \mathrm{Si}$ in 3 min. In addition, the roughness increased from $0.5 \pm 0.2$ to $5.0 \pm 0.5 \mathrm{~nm}$. Also, the film thickness increased by about $18 \%$. A DL model was subsequently used to simulate the evolution of the dielectric function and revealed that the resistivity increased from 14.9 to $186 \mu \Omega \mathrm{cm}$ while the MFP decreased from 36.6 to $2.7 \mathrm{~nm}$ in the same time period.

\section{B. $\mathrm{Cu} / \mathrm{TaN}_{x} /$ Si System}

The dynamic RTSE data was collected for samples S2 and $\mathrm{S} 3$, respectively. The growth process was simulated using a multilayer model as per the methodology outlined in the previous section $(\mathrm{Cu} / \mathrm{Si})$. The various layers and their thicknesses were deduced using a multilayer model and by simulating interdiffusion at the interface using a BEMT model. For S2, the multilayer model included an intermix underlayer $(3 \pm 1 \mathrm{~nm})$, a Ta-N layer $(30 \pm 3 \mathrm{~nm})$, another intermix layer $(4 \pm 1 \mathrm{~nm})$, and a $\mathrm{Cu}$ overlayer $(22 \pm 3 \mathrm{~nm})$. The intermix layers were modeled using a BEMT assuming that they are a mixture of the neighboring pure materials. For S3, the multilayer model consisted of an intermix layer $(3 \pm 1 \mathrm{~nm})$, a Ta-N layer $(50 \pm 6 \mathrm{~nm})$, another intermix layer $(4 \pm 1 \mathrm{~nm})$, and a $\mathrm{Cu}$ overlayer $(21 \pm 3 \mathrm{~nm})$. In addition, the analysis of the SE data using a DL model provided the resistivity and the electron MFP of the conduction electrons for $\mathrm{Cu}$ and $\mathrm{Ta}-\mathrm{N}$ (or TaN) for both samples (Figs. 4 and 5). In both samples, the measured values for the $\mathrm{Cu}$ resistivities decreased abruptly while those for the MFP increased in a manner similar to the one observed in the previous section $(\mathrm{Cu} / \mathrm{Si})$. We attribute the higher $\mathrm{Cu}$ resistivity values for the first few monolayers to the isolated islandlike morphology of the $\mathrm{Cu}$ film consistent with previous studies on ultrathin $\mathrm{Cu}$ films. ${ }^{14-17}$ The finite-size islands are separated from each other and the boundaries of the islands serve as scattering surfaces. Therefore, the conduction of the electrons occured mainly through the underlayer. ${ }^{18}$ Another major contributor to the lower MFP would be the phase mixing produced by

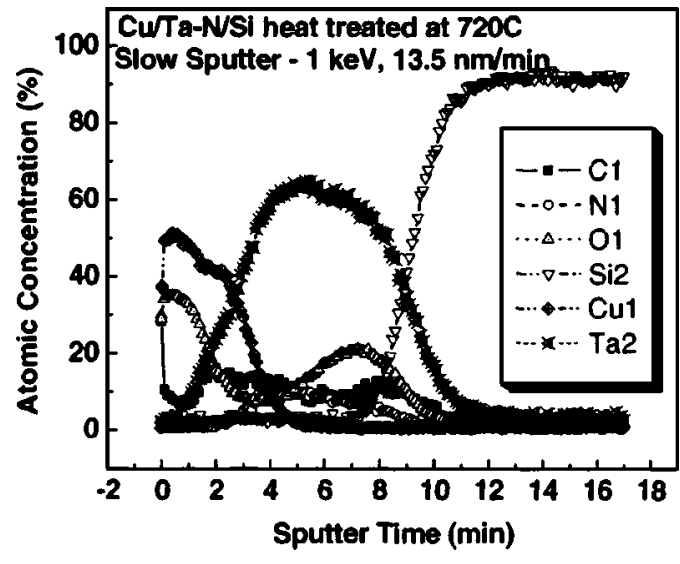

FIG. 9. AES depth profile for the $\mathrm{Cu} / \mathrm{Ta}-\mathrm{N} / \mathrm{Si}$ film.

our deposition conditions. Thus, the resistivity was high and the MFP was low. As film growth proceeded beyond a few monolayers, the $\mathrm{Cu}$ islands began to grow and coalesce, reducing the separation between islands and leading to the formation of a network of interconnected islands, which leads to a reduction in the resistivity and an increase in the MFP. Interestingly, the MFP of $\mathrm{Cu}$ reached a maximum value of $20 \mathrm{~nm}$ for a thickness of about $7 \mathrm{~nm}$ range and subsequently declined to reach values of $14 \mathrm{~nm}$. Similarly, the resistivity decreased to reach a minimum value of $29 \mu \Omega \mathrm{cm}$ and subsequently increased to reach a value of $\rho=35 \mu \Omega \mathrm{cm}$. For $\mathrm{Cu} / \mathrm{Si}$, the maximum MFP was much higher (MFP $=36 \mathrm{~nm})$ and the minimum resistivity was much lower $(\rho$ $=14.9 \mu \Omega \mathrm{cm}$ ) and did not change once these values were reached. The growth of a $\mathrm{Cu}$ film is a dynamic process during which both the surface roughness and the grain size change with the film thickness. It is possible that an increase in the surface roughness would account for the decrease in the MFP as the films grew thicker. In addition, a smaller grain size of $\mathrm{Cu}$ on Ta-N could account for the relatively higher values of resistivity (lower values of MFP) compared to $\mathrm{Cu}$ on $\mathrm{Si}$.

The evolution of the resistivity and of MFP of Ta-N and the TaN was very different from that of $\mathrm{Cu}$. For Ta-N, the initial values of the MFP were relatively high (MFP $=8.8 \mathrm{~nm}$ and $\rho=150 \mu \Omega \mathrm{cm}$ when $t=1.75 \mathrm{~nm})$. This is probably due to a growth process that is consistent with a Frank van Der Merwe or 2D-layer growth mode. In addition, the MFP increased slowly with the thickness. The MFP for TaN was in the subnanometer range because it is an intrinsic property of this material, which is an insulator. The measured resistivity and the MFP once the deposition process was completed was $830 \mu \Omega \mathrm{cm}$ and $0.70 \mathrm{~nm}$, respectively.

Figure 6 shows the x-ray diffraction (XRD) spectra for $\mathrm{S} 2$ and S3. These spectra indicated that the $\mathrm{Cu}(111)$ and $\mathrm{Ta}_{2} \mathrm{~N}(200)$ were the preferred orientations for $\mathrm{S} 2$ and that $\mathrm{Cu}(111)$ and $\mathrm{TaN}(111)$ were the preferred orientations for S3. Although the peak intensities were very weak, an attempt to fit the $\mathrm{Cu}$ diffraction peaks using a pseudo-Voigt function was made and the average grain sizes were subsequently calculated to be $20 \pm 5 \mathrm{~nm}$ (for both samples) from the widths 


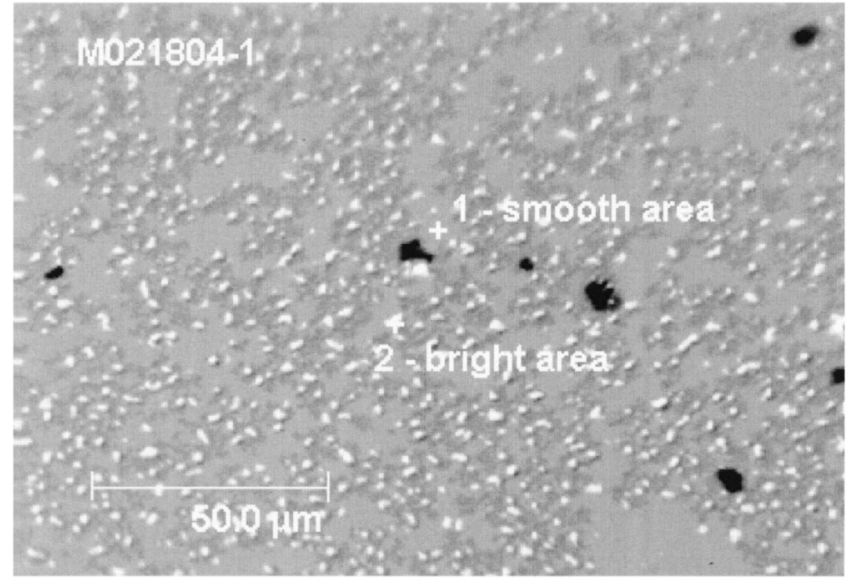

FIG. 10. SEM micrograph for the heat-treated $\mathrm{Cu} / \mathrm{TaN} / \mathrm{Si}$ film.

of the XRD peaks using the Scherrer formula. Grain boundary scattering could explain why the electron MFP for $\mathrm{Cu}$ on Ta-N (or TaN) did not exceed $20 \mathrm{~nm}$.

RBS measurements were carried out to obtain the compositional information about S2 and S3 before and after heat treatment (Figs. 7 and 8). During the annealing process, the temperature was increased between room temperature and $720^{\circ} \mathrm{C}$ with a ramp rate of $150{ }^{\circ} \mathrm{C} / \mathrm{min}$. The temperature was subsequently held at $720^{\circ} \mathrm{C}$ for $1.5 \mathrm{~h}$. The layer thicknesses deduced from the simulation of the RBS data using the RUMP program are shown in Table II. RBS measures the elemental ratios and yields the composition information with $1 \%-5 \%$ accuracy. Because the thickness of the films deduced from these elemental ratios depends on the uniformity of the film thicknesses, density of the phases, energy straggling, etc., a conservative estimate of error in the thickness is assumed to be $10 \%$. For S2, the annealing did not show any signs of interdiffusion although it resulted in an increase in the layer thickness due to oxidation. In contrast, annealing S3 resulted in a limited interdiffusion accompanied by a phase transformation as depicted by Fig. 8, though surprisingly, this sample oxidized much less.

The depth profile of the AES spectra were recorded after heat treatment for both structures. The spectrum for S2, shown in Fig. 9, confirms the results deduced from the RBS spectra, i.e., no interdiffusion occurred but the film oxidized.

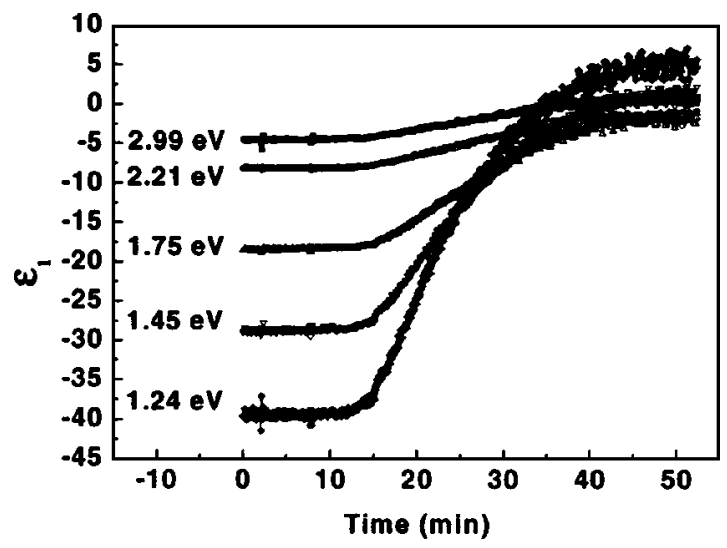

FIG. 11. Selected SE spectra measured during the heat treatment of the $\mathrm{Cu} / \mathrm{TaN} / \mathrm{Si}$ films.

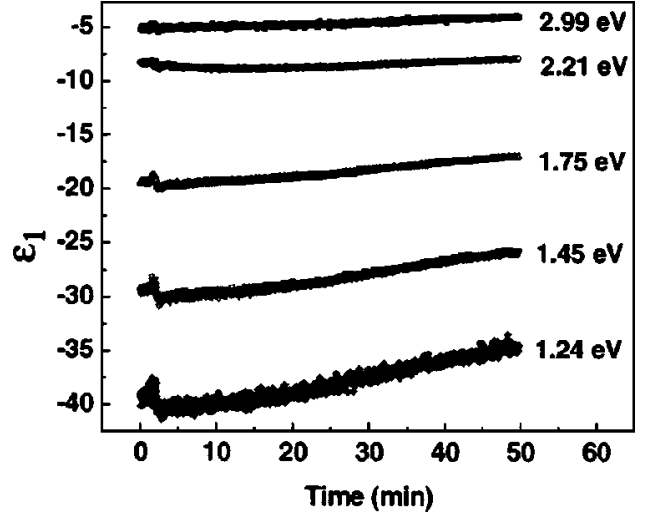

FIG. 12. Selected SE spectra measured during the heat treatment of the $\mathrm{Cu} / \mathrm{Ta}-\mathrm{N} / \mathrm{Si}$ films.

The SEM data showed that the films remained relatively smooth. In contrast, Fig. 10 shows a typical SEM micrograph of the $\mathrm{Cu} / \mathrm{TaN} / \mathrm{Si}$ after annealing at $720{ }^{\circ} \mathrm{C}$. Protrusions were observed on the surface indicating a severe reaction. These protrusions were presumably caused by $\mathrm{Cu}$ diffusion through localized weak points in the barrier and reacting with the underlying $\mathrm{Si}$ to form $\mathrm{Cu}_{3} \mathrm{Si}$. The depth profile of the AES did not reveal any phase transformation under the smooth areas but confirmed the formation of silicide phases under the protrusions in agreement with observations reported by other authors. ${ }^{6,19}$

Finally, the thermal stability of the films was investigated using RTSE. The pseudo-dielectric function of the $\mathrm{Cu} / \mathrm{TaN} / \mathrm{Si}$ (S3) changed dramatically from a metallic to an insulating character in a fashion similar to the one observed for the $\mathrm{Cu} / \mathrm{Si}$ (Fig. 11). In contrast, the $\mathrm{Cu} / \mathrm{Ta}-\mathrm{N} / \mathrm{Si}$ (S2) structure preserved its metallic character (Fig. 12). Very little change occurred and was attributed to the oxidation of the film, as previously indicated by the RBS measurements. A simulation using the BEMT or the DL was not attempted due to the complexity of the postannealing film architecture and the increased diffuse scattering at the very rough surfaces. Therefore, RTSE allows one to determine the thermal stability of metallization nanostructures, thereby avoiding the need to use destructive techniques such as AES and secondaryion-mass spectroscopy, which are widely used by the semiconductor industry. The knowledge of the dielectric function of the silicide materials is necessary to model the nanostructure and to obtain a quantitative information nondestructively.

\section{CONCLUSIONS}

In this work, the $\mathrm{Cu} / \mathrm{Si}$, the $\mathrm{Cu} / \mathrm{TaN} / \mathrm{Si}$, and the $\mathrm{Cu} / \mathrm{Ta}-\mathrm{N} / \mathrm{Si}$ structures were fabricated using an unbalanced magnetron sputtering. The RTSE was used to monitor the film growth and the heat treatment of these structures. The RTSE data was analyzed using a BEMT and a DL model. The BEMT model provided an information about film architecture (film thickness, layer structure, phase composition, and interface quality). The DL model provided extensive information regarding the optical and the electrical properties of the films (electron MFP, electrical resistivity, and band 
structure). The RTSE was also used to examine and to model any transformations observed during the annealing of the films. It was shown that the RTSE is a powerful technique to monitor the growth, thermal stability, and electronic properties of these structures in a noninvasive and nondestructive fashion. The extensive results provided through observation (qualitative) and modeling (quantitative) by the RTSE were confirmed using the more traditional destructive techniques, i.e., the RBS and the AES. More room is available to further enhance the effectiveness of the Ta- $\mathrm{N}$ structures as the diffusion barriers against the copper diffusion. This may be achieved by altering the deposition conditions in order to (1) decrease layer thicknesses (requirement of new generation interconnects); (2) minimize interface quality by increasing the flux and decreasing the energy of the bombarding ions; ${ }^{20}$ and (3) minimize the resistivity of both layers without affecting the performance of the structure.

\section{ACKNOWLEDGMENTS}

The authors would like to thank Professor Ivan Petrov, Dr. Nancy Finnegan, and Dr. Mauro Sardela for the XRD, the AES, and the RBS measurements, carried out in the Center for Microanalysis of Materials, University of Illinois, which is partially supported by the U.S. Department of Energy under Grant No. DEFG02-91-ER45439. They would also like to thank Clay Watts for designing and fabricating a substrate holder, which can be used at a high temperature.
This research was supported by an award from the Research Corporation and by the Materials Technology Center of Southern Illinois University.

${ }^{1}$ A. E. Kaloyeros and E. Eisenbraun, Annu. Rev. Mater. Sci. 30, 363 (2000).

${ }^{2}$ A. A. Istratov and E. R. Weber, J. Electrochem. Soc. 149, G21 (2002).

${ }^{3}$ Y. Wang, C. Zhu, Z. Song, and Y. Li, Microelectron. Eng. 71, 69 (2004).

${ }^{4}$ M. B. Takeyama, A. Noya, and K. Sakanishi, J. Vac. Sci. Technol. B 18, 1333 (2000)

${ }^{5}$ H. C. Kim and T. L. Alford, Thin Solid Films 449, 6 (2004).

${ }^{6}$ W.-F. Wu, K.-L. Ou, C.-P. Chou, and C.-C. Wu, J. Electrochem. Soc. 150, G83 (2003).

${ }^{7}$ A. Z. Moshfegh and O. Akhavan, Thin Solid Films 370, 10 (2000).

${ }^{8}$ S. M. Aouadi, M. Debessai, and P. Filip, J. Vac. Sci. Technol. B 22, 1134 (2004).

${ }^{9}$ P. Patsalas and S. Logothetidis, J. Appl. Phys. 93, 989 (2003).

${ }^{10}$ L. R. Doolittle, Nucl. Instrum. Methods Phys. Res. B 9, 344 (1985).

${ }^{11}$ J. A. Woollam Co., Inc., Guide to using WVASE32 (Lincoln Square Publishing Company, NE, 1997).

${ }^{12}$ F. Wootten, Optical Properties of Solids (Academic, New York, 1972).

${ }^{13}$ P. Patsalas and S. Logothetidis, Surf. Coat. Technol. 180, 421 (2004).

${ }^{14}$ S. M. Rossnagel and T. S. Kuan, J. Vac. Sci. Technol. B 22, 240 (2004).

${ }^{15}$ M. Brügemann, A. Masten, and P. Wibmann, Thin Solid Films 406, 294 (2002).

${ }^{16}$ E. V. Narnat, D. Nagakura, P.-I. Wang, and T. M. Lu, J. Appl. Phys. 91, 1667 (2002)

${ }^{17}$ W. Steinhgl, G. Schindler, G. Setinlesberger, and M. Engelhardt, Phys. Rev. B 66, 075414 (2002).

${ }^{18}$ M. Li, Y.-P. Zhao, and G.-C. Wang, J. Vac. Sci. Technol. A 18, 2992 (2000).

${ }^{19}$ K. Holloway, P. M. Fryer, C. Cabral, Jr., J. M. E. Harper, P. J. Bailey, and K. H. Kelleher, J. Appl. Phys. 71, 5433 (1992).

${ }^{20}$ J. Birch, F. Eriksson, G. A. Johansson, and H. M. Hertz, Vacuum 68, 275 (2002). 